\title{
Scoring systems for outcome prediction in patients with perforated peptic ulcer
}

Kenneth Thorsen ${ }^{1,2}$, Jon Arne Søreide ${ }^{1,2}$ and Kjetil Søreide ${ }^{1,2^{*}}$

\begin{abstract}
Background: Patients with perforated peptic ulcer (PPU) often present with acute, severe illness that carries a high risk for morbidity and mortality. Mortality ranges from 3-40\% and several prognostic scoring systems have been suggested. The aim of this study was to review the available scoring systems for PPU patients, and to assert if there is evidence to prefer one to the other.
\end{abstract}

Material and methods: We searched PubMed for the mesh terms "perforated peptic ulcer", "scoring systems", "risk factors", "outcome prediction", "mortality", "morbidity" and the combinations of these terms. In addition to relevant scores introduced in the past (e.g. Boey score), we included recent studies published between January 2000 and December 2012) that reported on scoring systems for prediction of morbidity and mortality in PPU patients.

Results: A total of ten different scoring systems used to predict outcome in PPU patients were identified; the Boey score, the Hacettepe score, the Jabalpur score the peptic ulcer perforation (PULP) score, the ASA score, the Charlson comorbidity index, the sepsis score, the Mannheim Peritonitis Index (MPI), the Acute physiology and chronic health evaluation II (APACHE II), the simplified acute physiology score II (SAPS II), the Mortality probability models II (MPM II), the Physiological and Operative Severity Score for the enumeration of Mortality and Morbidity physical sub-score (POSSUM-phys score). Only four of the scores were specifically constructed for PPU patients. In five studies the accuracy of outcome prediction of different scoring systems was evaluated by receiver operating characteristics curve (ROC) analysis, and the corresponding area under the curve (AUC) among studies compared. Considerable variation in performance both between different scores and between different studies was found, with the lowest and highest AUC reported between 0.63 and 0.98 , respectively.

Conclusion: While the Boey score and the ASA score are most commonly used to predict outcome for PPU patients, considerable variations in accuracy for outcome prediction were shown. Other scoring systems are hampered by a lack of validation or by their complexity that precludes routine clinical use. While the PULP score seems promising it needs external validation before widespread use.

Keywords: Perforated peptic ulcer, Scoring systems, Outcome prediction, Mortality, Morbidity

\section{Introduction}

Peptic ulcer disease is associated with potentially lifethreatening complications, including bleeding, perforation, penetration and obstruction. Perforation is the second most frequent complication after bleeding [1]. While the clinical picture of patients with perforated peptic ulcer (PPU) sometimes can be blurred by vague symptoms, most PPU patients present with overt symptoms and signs of peritonitis and eventually sepsis. Variations in the clinical

\footnotetext{
* Correspondence: ksoreide@mac.com

'Department of Gastrointestinal Surgery, Stavanger University Hospital, POB

8100, Stavanger, N 4068, Norway

${ }^{2}$ Department of Clinical Medicine, University of Bergen, Bergen, Norway
}

presentation as well as delay in diagnosis and work-up at admission to the hospital, may potentially cause a worsening of symptoms and a deterioration of the clinical condition, with a detrimental outcome. Still, a high risk for morbidity (20-50\%) and mortality (3-40\%) is encountered in surgically treated PPU patients [2-7]. About every fifth patient with PPU present with signs of sepsis and by a careful preoperative assessment of the patients' severity grade, appropriate management can be offered to achieve an optimal outcome of disease [8,9]. Currently, the ASA score and the Boey score are the most frequently used prognostic scoring systems in patients with PPU [10-14].

\section{Biomed Central}

(c) 2013 Thorsen et al.; licensee BioMed Central Ltd. This is an Open Access article distributed under the terms of the Creative Commons Attribution License (http://creativecommons.org/licenses/by/2.0), which permits unrestricted use, distribution, and reproduction in any medium, provided the original work is properly cited. 
Yet, the ASA score is a general surgical risk score not intended for PPU patients in particular. Moreover, the external validation of the Boey score is uncertain.

The aim of this study was to review the available scoring systems used for outcome prediction in PPU patients, and to evaluate if any scoring system has advantages and predictive power to be preferred in clinical practice on this group of patients.

\section{Material and methods}

We searched the Pub Med database by using the mesh terms; "perforated peptic ulcer", "scoring systems for morbidity and mortality", "risk factors", "outcome prediction" and the combinations of these terms. In addition we did a manual search from identified articles of relevance. We evaluated studies on PPU patients and related outcomes (morbidity and mortality), published in the English language between 2000 and 2012, and recognized the scores or combinations of scores that have been used in these studies. A few seminal articles published before 2000 were also taken into consideration. The study data were compared by a descriptive approach.

\section{Definitions}

Receiver operating characteristics curve (ROC) is a statistical method that measures diagnostic accuracy of a test and offers graphical display of the true positives versus the false positives. Area under the curve (AUC) is used to measure the "size" of the curve of prediction composed by the graphic display between the 'sensitivity' and the ' 1 -specificity' relationship. AUC can range from 0.5 to 1.0 and a result of 1.0 indicates a perfect discriminatory ability [15]. An AUC value $>0.8$ is considered good, a range between $0.60-0.80$ is considered as moderate, and an AUC value $<0.60$ is regarded as poor [16]. The ROC curve is calculated by using all possible score values as a potential cut-off value for a given outcome prediction (such as mortality), and displays the optimal cut-off point when sensitivity and specificity reaches an optimum for both values, by which the point on the ROC curved line is closest to the upper left corner on the curve.

\section{Results}

Ten different scoring systems (Table 1) used for prediction of outcomes for PPU patients were identified, including the Boey score [14], the Hacettepe score [17] the Jabalpur score [18], the Peptic Ulcer Perforation (PULP) score [19], the American Society of Anesthesiologists (ASA) score [20], the Charlson comorbidity index [21], the sepsis score [22], the Mannheim Peritonitis Index (MPI) [23], the Acute Physiology and Chronic Health Evaluation II (APACHE II) [24], the Simplified Acute Physiology Score II (SAPS II) [25], the Mortality Probability Models II (MPM II) [26] and the Physiological and Operative Severity Score for the enumeration of Mortality and Morbidity physical subscore (POSSUM-phys score) [27]. In five studies, comparison of various scoring systems for outcome prediction was done by ROC-analyses with reporting on the area under the curve (AUC) [10,16,18,19,22]. A few studies presented specificity and sensitivity, relative risks (RR) and odds ratios (OR), while most studies reported on performance by calculation of the chi square test.

\section{Scoring systems aimed at prediction of outcome in PPU}

The Boey score was the first score directly aimed at mortality prediction for perforated peptic ulcer [14]. The original work by Boey et al stated that delay of surgery after onset of symptoms for more than 48 hours, shock upon admission and a high degree of comorbidity, were associated with a $100 \%$ mortality when all factors where present. Eventually, the delay of surgery was adjusted to 24 hours, and the scoring system was validated in a cohort from Hong Kong [14,28].

The Hacettepe score was also developed for PPU patients and comprises four factors (Table 1) [17]. This study evaluated 173 patients from Turkey and found the Hacettepe score to be equivalent to the Mannheim Peritonitis Index (MPI), with a sensitivity of $83 \%$ and specificity of $94 \%$ for mortality prediction. The sensitivity for the MPI in this study was $75 \%$ and the specificity $96 \%$. Eventually, this score was used in a study from India, as elaborated below $[17,18]$.

The Jabalpur score was based on a study on 140 patients from India, with a mean age of 39 years. This score takes into account six factors, which are all assessable preoperatively. Both morbidity and mortality were predicted accurately, based on a high AUC value (Table 2) [18].

Most recently, the Peptic Ulcer Perforation (PULP) score has been introduced as a scoring system for perforated peptic ulcer. This score is based on a nationwide study from Denmark and included 2668 PPU patients with a median age of 70.9 years, where $55 \%$ was female. Seven factors are taken into account, with weighted points applicable for each factor, with a maximum sum of 18 points being the highest possible. The optimal cutoff point was found to be 7 points, which gives a positive predictive value (PPV) of $25 \%$ for those with $0-7$ points, and a PPV of $38 \%$ for the group with 8 or more points [19]. The PULP study also compared different systems elaborated below.

\section{General scores of comorbidity}

The ASA score introduced in 1941 and intended for preoperative assessment of patients' fitness level, is the oldest available scoring system $[20,29]$. ASA score is frequently reported together with other descriptive patient data 
Table 1 Scoring systems used for outcome prediction in perforated peptic ulcer

\begin{tabular}{|c|c|c|c|c|}
\hline $\begin{array}{l}\text { Scoring systems } \\
\text { (reference) }\end{array}$ & $\begin{array}{l}\text { Year of } \\
\text { report }\end{array}$ & $\begin{array}{l}\text { Target } \\
\text { population }\end{array}$ & Outcome measured & Parameters evaluated \\
\hline Boey [14] & 1987 & $\begin{array}{l}\text { Patients with } \\
\text { PPU }\end{array}$ & 30 day mortality & $\begin{array}{l}\text { Presentation } \geq \text { or }<24 \text { hours; presence of preoperative shock; } \\
\text { level of comorbidity. }\end{array}$ \\
\hline $\begin{array}{l}\text { Hacettepe score } \\
{[17]}\end{array}$ & 1992 & $\begin{array}{l}\text { Patients with } \\
\text { PPU }\end{array}$ & 30 day mortality & $\begin{array}{l}\text { Presence of serious medical illness, acute renal failure, } \\
\text { white blood cell count, male gender }\end{array}$ \\
\hline $\begin{array}{l}\text { Jabalpur score } \\
{[18]}\end{array}$ & 2003 & $\begin{array}{l}\text { Patients with } \\
\text { PPU }\end{array}$ & 30 day mortality & $\begin{array}{l}\text { Time from perforation to operation, mean systolic blood } \\
\text { pressure preoperatively, heart rate, serum creatinine, age, } \\
\text { comorbidity }\end{array}$ \\
\hline PULP [19] & 2012 & $\begin{array}{l}\text { Patients with } \\
\text { PPU }\end{array}$ & 30 day mortality & $\begin{array}{l}\text { Presentation } \geq \text { or }<24 \text { hours; presence of preoperative shock; } \\
\text { ASA score, presence of aids, active malignancy, liver failure; } \\
\text { serum creatinine }>130 \mathrm{mmol} / \mathrm{l}\end{array}$ \\
\hline ASA [20] & 1941 & $\begin{array}{l}\text { General surgical } \\
\text { populations }\end{array}$ & $\begin{array}{l}\text { Preoperative risk assessment } \\
\text { for surgical patients }\end{array}$ & Degree of comorbidity and present systemic disease \\
\hline $\begin{array}{l}\text { Charlson } \\
\text { comorbidity index } \\
{[21]}\end{array}$ & 1987 & $\begin{array}{l}\text { General surgical } \\
\text { populations }\end{array}$ & $\begin{array}{l}\text { Prediction of } 1 \text { year mortality } \\
\text { for hospitalized patients }\end{array}$ & Weighting of different comorbidities \\
\hline $\begin{array}{l}\text { Mannheim } \\
\text { peritonitis index } \\
{[23]}\end{array}$ & 2002 & $\begin{array}{l}\text { General } \\
\text { peritonitis }\end{array}$ & $\begin{array}{l}\text { Peroperative prediction of outcome } \\
\text { in patients with peritonitis }\end{array}$ & $\begin{array}{l}\text { Age, gender, organ failure, duration of peritonitis, } \\
\text { site of perforation, diffuse peritonitis, level of exudate }\end{array}$ \\
\hline APACHE II [24] & 1985 & $\begin{array}{l}\text { Critically ill } \\
\text { patients }\end{array}$ & $\begin{array}{l}\text { Prediction of outcome for } \\
\text { ICU patients }\end{array}$ & $\begin{array}{l}\text { Aids, metastatic cancer, liver failure, immunosuppression, } \\
\text { chronic renal insufficiency, haemotologic malignancy, } \\
\text { lymphoma, leukemia, age, heart rate, systolic blood pressure, } \\
\text { respiratory rate, temperature, GCS, WBC, creatinine, blood gas, } \\
\text { potassium, sodium, patient origin }\end{array}$ \\
\hline SAPS II [25] & 1993 & $\begin{array}{l}\text { Critically ill } \\
\text { patients }\end{array}$ & $\begin{array}{l}\text { Prediction of outcome for } \\
\text { ICU patients }\end{array}$ & $\begin{array}{l}\text { Aids, metastatic cancer, haemotologic malignancy, age, } \\
\text { heart rate, systolic blood pressure, temperature, GCS, } \\
\text { urine output, WBC, bilirubin, urea, Potassium, sodium, } \\
\text { Patient origin }\end{array}$ \\
\hline MPM II [26] & 1993 & $\begin{array}{l}\text { Critically ill } \\
\text { patients }\end{array}$ & $\begin{array}{l}\text { Prediction of outcome for } \\
\text { ICU patients }\end{array}$ & $\begin{array}{l}\text { Metastatic cancer, liver failure, chronic renal insufficiency, } \\
\text { leukemia, age, acute renal failure, arrythmias, heart rate, } \\
\text { Gl bleeding, GCS, intracranial mass effect, cerebrovascular } \\
\text { accident, cpr prior to admission, mechanical ventilation }\end{array}$ \\
\hline POSSUM [37] & 1991 & Surgical patients & $\begin{array}{l}\text { Prediction of outcome } \\
\text { (mortality) for surgical } \\
\text { patients }\end{array}$ & $\begin{array}{l}\text { Respiratory history; cardiac signs; age; heart rate; } \\
\text { systolic blood pressure; ecg; GCS; operative severity; } \\
\text { multiple procedures, total blood loss, peritoneal soiling, } \\
\text { finding of peroperative malignancy; elective or acute surgery, } \\
\text { WBC, Hb, urea, potassium, sodium }\end{array}$ \\
\hline
\end{tabular}

Peptic ulcer perforation score (PULP score).

American society of anesthesiologists (ASA) score.

Acute physiology and chronic health evaluation II (APACHE II).

Simplified acute physiology score II (SAPS II).

Mortality probability models II (MPM II).

Physiological and operative severity score for the enumeration of mortality and morbidity (POSSUM) score.

Glasgow coma scale (GCS).

White blood cell count (WBC).

Gastrointestinal bleeding (Gl bleeding).

Hemoglobin $(\mathrm{Hb})$.

including age, gender, and various physiologic parameters, but this classification has no specific role in outcome prediction of patients with PPU per se.

The Charlson comorbidity index was developed to stratify comorbidity into different risk groups by assigning scores to various illnesses [21]. The Charlson index is a widely used scoring system and considers 19 conditions deemed clinically important, and they are each given 1 to 6 points due to high or low morbidity grade. Cerebrovascular disease is given 1 point, severe liver disease 3 points and metastatic cancer and AIDS are given 6 points. The Charlson index was initially suggested for prediction of long-term mortality. However, later studies have found it to be useful also in prediction of in-hospital morbidity and mortality [30,31]. One study also used the Charlson comorbidity index to predict outcome in PPU patients. A highly significant association between a medium or high Charlson score and 30-day mortality was observed, with an odds ratio (OR) of 4.17 for high score ( 3 or more points on the Charlson score) and an OR of 3.99 for medium score (1-2 points on the Charlson score) [32]. However, identification of any other PPU studies to confirm the obtained results by use of this particular score was not possible. 
Table 2 Scoring accuracy of mortality prediction in PPU patients

\begin{tabular}{|c|c|c|c|c|c|}
\hline \multirow{4}{*}{$\begin{array}{l}\text { Scoring systems } \\
\text { evaluated }\end{array}$} & Mishra et al [18] & Lohsiriwat et al [10] & Koc et al [16] & Møller et al [19] & Buck et al [22] \\
\hline & Mortality rate & Mortality rate & Mortality rate & Mortality rate & Mortality rate \\
\hline & $10.7 \%$ & $9.0 \%$ & $10.6 \%$ & $27.0 \%$ & $17.0 \%$ \\
\hline & \multicolumn{5}{|c|}{ Area under the ROC Curve (AUC) } \\
\hline ASA & & 0.91 & & 0.78 & 0.73 \\
\hline Boey & 0.85 & 0.86 & & 0.70 & 0.63 \\
\hline Apache II & & & 0.87 & & 0.76 \\
\hline SAPS ॥ & & & 0.86 & & \\
\hline MPM II & & & 0.98 & & \\
\hline Hacateppe score & 0.72 & & & & \\
\hline Jabalpur score & 0.92 & & & & \\
\hline MPI & & 0.84 & & & \\
\hline Modified Apache II & 0.84 & & & & \\
\hline Modified MPI & 0.85 & & & & \\
\hline PULP & & & & 0.83 & \\
\hline Sepsis score & & & & & 0.69 \\
\hline $\begin{array}{l}\text { AUC denotes area un } \\
\text { regarded as poor. } \\
\text { ASA, American society } \\
\text { APACHE II denotes AC } \\
\text { Modified APACHE II, A } \\
\text { SAPS, Simplified acute } \\
\text { MPM, Mortality proba } \\
\text { MPI denotes Mannhe } \\
\text { Modified MPI, MPI calc }\end{array}$ & $\begin{array}{l}\text { curve . An AUC value } \\
\text { sthesiologists (ASA) sc } \\
\text { /siology and chronic I } \\
\text { II calculated when no } \\
\text { logy score II (SAPS II). } \\
\text { odels II (MPM II). } \\
\text { onitis index. } \\
\text { when no available blc }\end{array}$ & $\begin{array}{l}\text { considered good, a ran } \\
\text { veluation II. } \\
\text { blood gas. }\end{array}$ & $0.60-0.80$ is $c$ & as moderate, and & alue $<0.60$ is \\
\hline
\end{tabular}

The Sepsis criteria are easy to calculate preoperatively and the presence of sepsis is fulfilled if two or more of the following parameters are present, when infection is confirmed or highly likely; temperature $>38^{\circ} \mathrm{C}$ or $<36^{\circ} \mathrm{C}$ respiratory rate $>20$ per minute or $\mathrm{PCO}_{2}<4.3 \mathrm{kPa}$, heart rate $>90$ per minute, White cell count $>12.0 \times 109$ or $<4.0 \times 109$ [33].

Obviously this system is widely used in several aspects of medicine, but has also been applied to predict outcome in a PPU cohort, as elaborated below [22].

The Mannheim Peritonitis Index (MPI) consists of seven factors that are more directly related to the operative findings. As the name implies, the design was specifically intended for surgical patients presenting with peritonitis. It comprises both preoperative and perioperative conditions, and has been found to predict morbidity well, but less so in prediction of mortality for PPU patients $[10,23]$.

\section{Intensive care unit (ICU) systems}

The Acute physiology and chronic health evaluation II (APACHE II) score is a common score globally and the most used ICU scoring system in the USA. It comprises twelve different physiological measurements, age and previous health status, and was originally designed to categorize ICU patients according to risk. The system gives an increasing amount of points for extreme values (high or low), between $0\left(36.0^{\circ} \mathrm{C}-38.4^{\circ} \mathrm{C}\right)$ and $4\left(\geq 41^{\circ} \mathrm{C}\right.$ and $\leq 29.9^{\circ} \mathrm{C}$ ). Originally this score was found to perform well amongst ICU patients [24]. Later, it was also applied to predict outcome in PPU patients. One study from the USA [34] reported on zero mortality in PPU patients with scores less than 11 points, and a 35\% mortality rate in patients with at least 11 points, which indicates this as a useful cut-off. Others have tried different cut-off values without finding these to be more useful. However the APACHE II score is a rather complex system needing mathematical equations to calculate and a minimum of 24 hours to assess all factors. This may pose implications and concerns for its clinical usefulness and availability. Nevertheless, APACHE II has been shown to predict outcome well also for PPU patients [16,24,34].

The Simplified acute physiology score II (SAPS II) is designed for predicting outcome in ICU patients and consists of 17 variables. It was developed in the 80s and a revised version was introduced in 1993 [25]. The SAPS II system is frequently used for outcome prediction in critically ill patients in Europe and Scandinavia, and has many similarities with the APACHE II system [25]. Both systems are rather complex, with a number of factors incorporated in the calculations, including physiologic parameters. The SAPS II system predicts mortality and morbidity well, but also seems more suitable for ICU patients. Nevertheless, this score performed well for outcome prediction of PPU patients [16].

The Mortality probability models II (MPM II) was designed for prediction of outcome in ICU patients. MPM II 
assesses the presence or not of 14 different clinical factors, several related to systemic perfusion [26]. The MPM II predicted mortality better then both SAPS II and APACHE II in one study [16]. However this study was rather small and skewed with basically younger male patients, which is in contrast to current PPU cohorts. While some studies from Asia and Africa have presented similar patient characteristics [35,36], recent studies from Scandinavia and Northern Europe have presented data with a 1:1 male/female ratio and median age close to 70 years [19,27]. Moreover, the MPM II is a rather complex system, thus suboptimal for a pre-operative calculation in the clinical context PPU patients present.

The Physiological and Operative Severity Score for Enumeration of Mortality and Morbidity (POSSUM score) consists of 12 factors based on the patients physiological state and 6 factors regarding operative conditions. These factors are then entered into two mathematical equations for risk assessment [37]. The POSSUM score was designed for outcome prediction in ICU patients, and is widely used in the UK. The original POSSUM score tended to overestimate mortality for low risk groups. The PortsmouthPOSSUM (P-POSSUM) was therefore designed to adjust for this [38]. Prediction of mortality in patients undergoing emergency laparotomy was improved by the P-POSSUM score, compared to the original POSSUM score $[38,39]$. The POSSUM-phys score, which is the physiologic subscore, comprises only the 12 physiologic parameters, which can be assessed preoperatively. Only one study was found that applied POSSUM-phys to PPU patients. In this study 261 PPU patients with a mean age of 67 years were evaluated and the POSSUM-phys score predicted both mortality and morbidity [27]. The POSSUM-phys score, in contrast to the POSSUM score, can be assessed preoperatively. However, with regard to PPU patients, we have not encountered any studies comparing POSSUMphys score with other scoring systems.

\section{Isolated risk factors for morbidity and mortality in PPU}

In a large systematic review of pre-operative prognostic factors in PPU patients, Møller et al identified 50 prognostic studies evaluating overall 37 prognostic factors in a population total of 29,782 patients [40]. They deemed the overall methodological quality to be acceptable, yet only two-thirds of the studies provided confounderadjusted estimates in the multivariable analyses. Very few of the included studies investigated all, or the majority of, the prognostic factors included in the review. Some of the markers were only investigated in a few studies, and overall, the diversity and spread across the studies were considerable for most markers.

Nonetheless, adjusted pooled relative risks showed evidence for an association between mortality and older age, comorbidity, and the use of medications such as
Non Steroid Anti Inflammatory Drugs (NSAIDs), steroids and immunosuppressives [40]. Further predictive factors associated with a poor prognosis included shock upon admission, pre-operative metabolic acidosis, tachycardia, elevated respiratory rate, acute renal failure, low serum albumin level, high ASA score, and a preoperative time-delay $>24$ hours. Notably, several of the scoring systems proposed (Table 1) include one or several of these factors, but usually not all.

\section{Studies comparing several scoring systems for outcome prediction in PPU patients}

Five studies were identified where AUC values were compared between different scoring systems. Mortality prediction varied from 0.63 to 0.98 for the different systems evaluated in these studies and these are presented in Table $2[10,16,18,19,22]$.

In another study from Chicago, including $436 \mathrm{PPU}$ patients, the Boey score was compared to the APACHE II score [41]. The Boey score predicted mortality, but failed to predict morbidity. Moreover, the Boey score predicted conversion from laparoscopy to laparotomy, with a conversion encountered in $81.8 \%$ of Boey 2 score patients. The APACHE II was found to predict both morbidity and mortality. However, no AUC or relative risks were calculated and of such it is not directly comparable to other studies [41].

A report from Finland in the early 2000s included 280 PPU patients [23] and MPI predicted postoperative morbidity better than both the ASA and the Boey score. But the Boey score predicted mortality better than both the ASA score and the MPI. The authors used likelihood ratios to discriminate, but no AUC testing was done in this study.

\section{Accuracy of morbidity prediction}

We identified only two studies that reported AUC values for morbidity prediction $[10,22]$. Lohsiriwat et al defined morbidity as some form of complication and found AUC values of 0.80 for both the ASA and the Boey score, while MPI performed poorest with an AUC of 0.74 [10]. Buck et al defined septic shock and ICU admission as secondary endpoints and found following AUC values; for septic shock the AUC values were 0.67 for the ASA score, 0.72 for the Boey score, 0.74 for the sepsis score and 0.78 for the APACHE II score. For ICU admission the AUC values were 0.69 for the ASA score, 0.64 for the Boey score, 0.72 for APACHE II score and 0.64 for the sepsis score. Overall the APACHE II performed best for prediction of the two chosen secondary endpoints.

An overview of scoring systems, with mortality figures, published in various studies since the year 2000 , are presented in Table $3[4,7,10,16,18,19,23,27,32,35,36,42-59]$. 


\section{Discussion}

In this review we identified four scoring systems that have been developed specifically for prediction of outcome in PPU patients. However, several other general scores have been applied on this particular group of patients, although these scores have a non-specific design for PPU patients. We also identified several factors that make direct comparison of results and pooling of patient populations for assessment of outcome prediction difficult or impossible. Among these obstacles are time and sociodemographic differences and differences in score design and complexity. Some factors of these barriers are further discussed below.

\section{Implications of age on score performance}

The Boey score was developed from a study population with a median age of 51 years [14]. However, the age of PPU patients in recent studies from Europe have been considerably higher $[19,27,43,45]$, and age has been shown to be an isolated predictor for mortality in PPU patients $[4,19,40,43]$. Also, in the identified studies on mortality of PPU patients published the last decade, the 30 day mortality was at least $14 \%$ when age was mean or median $>60$ years $[4,19,27,32,43,45,48]$, in contrast to a decreased mortality between $3 \%$ and $14 \%$ in patient series with a mean or median age of $<60$ years $[7,10,16,23,36,44,47]$. Hence, the Boey risk score may not be as suitable for the older age groups as for the younger. As pointed out by others [22], there is also a weakness in its crudeness, including the definition of shock with a systolic blood pressure $<90 \mathrm{~mm} \mathrm{Hg}$ in the original study by Boey. In contrast, shock is usually defined by a combination of systolic blood pressure $\leq 100 \mathrm{~mm} \mathrm{Hg}$ and tachycardia, defined as a pulse $\geq 100$ per minute $[19,43]$. Thus, the Boey score may vary due to the definitions used. Nevertheless, several studies have found the Boey score to be a good predictor of mortality in PPU patients $[10,19,23]$. The Boey score was specifically designed for PPU patients, and while definitions are of some concern, the simplicity makes it very quick to calculate which is an advantage. Of note, the Boey score has not performed as well in predicting morbidity $[10,60,61]$.

\section{Differences in sociodemographic regions}

The Hacettepe score has been applied in two different studies with varying results and not better than the other systems used. It evaluates four factors and should be feasible to assess. However, $77 \%$ of the patients were $<50$ years of age and $94 \%$ were men. Similar PPU patient groups are found in other developing countries, but the patient demography is quite different in nondeveloping countries, with older age and minor differences between genders.

The Jabalpur score performed a high AUC score in the only study reporting it [18]. But the patient group was among the youngest with a mean age of 39 years with 98\% males. Therefore, it seems more applicable in regions with similar demography. When these two systems were tested in cohorts in India and Turkey, the Jabalpur system performed superior to the Hacettepe score $[17,18]$.

The nationwide PULP study is the largest recent study evaluating outcome prediction for PPU patients. Hence the external validity may be stronger, at least for comparable, western populations with demography similar to Denmark. The PULP score incorporates both the ASA score and the Boey score and can be evaluated preoperatively. Since it does incorporate both these systems, one would expect the PULP score to perform at least as well as the other systems on their own. Indeed, the PULP score did perform somewhat better, with slightly higher AUC values than both the ASA score and the Boey score in predicting morbidity and mortality [19]. However a validation of this system is needed.

Furthermore, the PPU systems found in the literature and presented in this review differ in many ways. The Boey score [14]was originally done on American patients in the early $80 \mathrm{~s}$, the Hacettepe score [17] on a Turkish population in the early 90s, the Jabalpur score [18] on an Indian population in the early 2000s and the PULP score [19] in Denmark in the late 2000. These studies differ in geography, mean age and decade presented, which means that further validation is recommended before any scoring system can be applied to a cohort different from the population of development.

\section{Comparing AUC values}

When comparing AUC values from ROC analyses from different studies, several limitations have to be considered. For one, different inclusion criteria and patient characteristics will potentially bias direct comparison of AUC values among studies. Hence, comparing ROC curve analysis and AUC values is best done on the same mix of patients [62]. A prediction model is made from fitting the data in a patient series by the means of logistic regression. Data included in such models may differ between studies, which may hamper comparison of AUC values of scoring systems from different studies.

Second, the number and the ratio of outcome events to the study population will influence the AUC accuracy and its precision. The PULP study included 2668 patients and with a mortality rate of $27 \%$ ( $n=720$ patients) as the evaluated outcome. Too few such outcome events in any given study will make logistic regression problematic and unreliable, with the confounding factors having a greater influence and thus a bias on the results. As a comparably large sample size, the PULP study may have higher power and reliability, than the other four studies comparing AUC values. However, the patient charac- 
Table 3 PPU studies reporting on 30-day mortality

\begin{tabular}{|c|c|c|c|c|c|c|}
\hline Study (reference) & Country & $\begin{array}{l}\text { Study } \\
\text { period }\end{array}$ & $\begin{array}{l}\text { Number of } \\
\text { patients }\end{array}$ & $\begin{array}{l}\text { Mortality rate, } \\
\text { n (\%) }\end{array}$ & Age, mean & Score system used \\
\hline Arici et al [50] & Italy & 1991-2004 & 147 & $14 \%$ & 52 (median) & Boey \\
\hline Arveen et al [36] & India & $2006-2008$ & 328 & $9 \%$ & 43 & ASA \\
\hline Bae et al [7] & Korea & 2006-2007 & 4258 & $3 \%$ & $\begin{array}{l}74 \% \text { younger than } \\
60 \text { years of age }\end{array}$ & No score system \\
\hline Bas et al [51] & Belgium & 1998-2004 & 97 & $5 \%$ & 39 & No score system \\
\hline Bin-Taleb et al [52] & Yemen & 1997-2006 & 156 & $4 \%$ & 39 & No score system \\
\hline Chalya et al [56] & Tanzania & 2006-2011 & 84 & $11 \%$ & 28 (median) & No score system \\
\hline Christensen et al [2] & Denmark & $1991-2003$ & 2061 & $25 \%$ & $\begin{array}{l}61 \% \text { older than } \\
65 \text { years of age }\end{array}$ & No score system \\
\hline Dakubo et al [35] & Ghana & 1998-2002 & 326 & $11 \%$ & 41 & No score system \\
\hline Egberts et al [27] & Germany & 1993-2005 & 261 & $24 \%$ & 67 (median) & Possum-phys \\
\hline Forsmo et al [46] & Norway & $1992-2003$ & 102 & $22 \%$ & 71 (median) & ASA \\
\hline Hemmer et al [43] & $\begin{array}{l}\text { The } \\
\text { Netherlands }\end{array}$ & $2000-2005$ & 272 & $16 \%$ & 62 & ASA \\
\hline Kamani et al [57] & Iran & 1996-2005 & 56 & $5 \%$ & 50 & No score system \\
\hline Kim et al [49] & Korea & $2005-2010$ & 142 & $6 \%$ & 57 & ASA \\
\hline Koc et al [16] & Turkey & $2005-2006$ & 75 & $11 \%$ & 44 (median) & $\begin{array}{l}\text { APACHE } \|, \text { APACHE II SAPS } \| \text {, } \\
\text { MPM ॥ }\end{array}$ \\
\hline Kocer et al [47] & Turkey & 2001-2004 & 269 & $9 \%$ & 43 & ASA \\
\hline Kujath [48] & Germany & $1996-2000$ & 102 & $14 \%$ & 69 & ASA \\
\hline Larkin et al [45] & Ireland & 1998-2007 & 76 & $20 \%$ & 60 & ASA \\
\hline Lohsiriwat et al [10] & Thailand & 2001-2006 & 152 & $9 \%$ & 52 & Boey, ASA, MPI \\
\hline Makele et al [23] & Finland & $1979-2000$ & 280 & $14 \%$ & 58 & Boey, ASA, MPI \\
\hline \multirow[t]{3}{*}{ Mishra et al [18] } & India & 1999-2001 & 140 & $11 \%$ & 39 & Apache II \\
\hline & & & & & & MPI \\
\hline & & & & & & Jabalpur \\
\hline $\begin{array}{l}\text { Montalvo-Jave et al } \\
\text { [53] }\end{array}$ & Mexico & $2006-2008$ & 30 & $17 \%$ & 57 & No score system \\
\hline Muslu et al [58] & Turkey & 1998-2005 & 126 & $4 \%$ & 51 & No score system \\
\hline Møller et al [19] & Denmark & 2003-2009 & 2668 & $27 \%$ & 71 (median) & PULP, ASA, Boey \\
\hline Nasio/Saidi [59] & Kenya & 2005-2006 & 44 & $9 \%$ & 35 & No score system \\
\hline Noguiera et al [44] & Portugal & 1990-2000 & 210 & $10 \%$ & 53 (median) & No score system \\
\hline \multirow[t]{2}{*}{ Rajesh et al [55] } & India & 2006-2011 & 180 & $13 \%$ & $<50$ years & Apache II \\
\hline & & & & & & Boey \\
\hline Subedi et al [54] & Nepal & 2002-2004 & 145 & $7 \%$ & 46 & No score system \\
\hline Taha et al [32] & Scotland & 1997-2006 & 270 & $19 \%$ & 64 (median) & Charlson comorbidity index \\
\hline \multirow[t]{2}{*}{ Thorsen et al [4] } & Norway & 2003-2009 & 114 & $16 \%$ & 67 (median) & ASA \\
\hline & & & & & & Boey \\
\hline
\end{tabular}

Table sorted alphabetically by study author's name.

Mortality rates and age are rounded up/down.

American society of anesthesiologists (ASA) score.

Acute physiology and chronic health evaluation II (APACHE II).

Simplified acute physiology score II (SAPS II).

Mortality probability models II (MPM II).

Mannheim peritonitis index (MPI).

Peptic ulcer perforation (PULP) score.

Physiological and operative severity score for the enumeration of mortality and morbidity physical sub-score (POSSUM-phys score). 
teristics in the PULP cohort differ from the other studies, which may influence the external validity. Thus, this model may not necessarily work well for other cohorts, and should thus be tested externally.

Lastly, timing of collection of the score variables is another important issue to consider when a scoring system for outcome prediction should be chosen. The more information that is available, the better would the performance of the score be expected. Hence a post-operative score would likely perform better as compared to a pre-operative or a peri-operative scoring system.

\section{Complexity of scores}

The ASA score is in contrast to the ICU systems simple to calculate, and it has been shown in various studies to predict both morbidity and mortality in general surgical patients $[10-13,19]$. Even though the ASA score neither was designed for, nor solely functions as a PPU score, it is widely used in PPU studies evaluating outcomes $[4,10,19]$. The ASA score has been shown to predict mortality well in several groups of patients, included for PPU patients $[10,18,19,47]$. The AUC values reported vary from 0.73 to 0.91, but the vast majority does not report AUC values or other parameters that make it possible to compare different studies. The main problem of the ASA score has been the inter-observer variability $[63,64]$.

The MPI is a more complex system and must be obtained during or after surgery, which is regarded challenging. However it has been shown to predict both morbidity and mortality, although to a varying degree. Only one study reported an AUC value for MPI (0.84), which is considered good [16], but both the ASA score and the Boey score performed better in this study [10].

Four ICU systems that were developed for outcome prediction of critically ill patients have been applied to PPU patients in one or more studies. In addition one study used the Charlson comorbidity index. But the complexity of these systems seems to limit the implementation in a general clinical setting. The APACHE II score is most frequently reported, but is still no common system used for PPU patients in general. They have all been shown to predict outcome for PPU patients, but to varying degree. And since only the fewest studies actually report on AUC values or other values that can be compared to others, data are sparse. MPM II performed the highest AUC value of all the scoring systems regarding mortality prediction with 0.98 , which is nearly perfect. However, this study was small and skewed, with mostly younger male patients, with a low mortality rate. Hence, its validity to patients with a different age and demographic patterns is highly questionable.

The Sepsis score has an important status in emergency medicine and is easy and rapid to calculate. Early recognition of the systemic inflammatory response syndrome
(SIRS) and prompt goal directed therapy, including perioperative and postoperative, can be of paramount importance and may influence outcome [9,33]. Probably, treatment delay in PPU patients, one of the factors in both the Boey score and the PULP score, is actually a surrogate marker for imminent sepsis. Also the presence of electrolyte disturbances, hypoalbuminemia, anemia, kidney failure, leukocytosis and shock can all be seen as part of the sepsis syndrome in a condition like perforated peptic ulcer. The sepsis score has also been found to predict outcome in PPU patients, but less so than most of the other scores evaluated [22].

\section{Conclusions}

While no scoring system was ideal and all were hampered by certain limitations, a few scores appeared easily applicable in clinical practice. The Boey score and the ASA score are most commonly applied in the current literature to predict outcomes for PPU patients, but both demonstrate variable accuracy. While the PULP score seems promising, a validation is pending before a general application can be recommended.

\section{Abbreviations}

PPU: Perforated peptic ulcer; ASA score: American society of

anesthesiologists score; ROC: Receiver operating characteristics curve; AUC: Area under the curve; MPI: Mannheim peritonitis index; APACHE I: Acute physiology and chronic health evaluation I; SAPS I: Simplified acute physiology score II; MPM II: Mortality probability models II; POSSUM- phys score: Physiological and operative severity score for the enumeration of mortality and morbidity phys score; OR: Odds ratio; ICU: Intensive care unit; NSAIDS: Non steroid anti inflammatory drugs; SIRS: Systemic inflammatory response syndrome.

\section{Competing interests}

The authors declared that they have no competing interest.

\section{Authors' contributions}

KT and KS planned and designed the study. KT did the litterature search and drafted the manuscript. KS and JAS revised the article. All authors read, revised and approved the final manuscript.

Received: 21 December 2012 Accepted: 4 April 2013

Published: 10 April 2013

\section{References}

1. Milosavljevic T, Kostic-Milosavljevic M, Jovanovic I, Krstic M: Complications of peptic ulcer disease. Dig Dis 2011, 29(5):491-493.

2. Christensen S, Riis A, Norgaard M, Sørensen HT, Thomsen RW: Short-term mortality after perforated or bleeding peptic ulcer among elderly patients: a population-based cohort study. BMC Geriatr 2007, 7:8.

3. Christiansen C, Christensen S, Riis A, Thomsen RW, Johnsen SP, Tonnesen E, Sorensen HT: Antipsychotic drugs and short-term mortality after peptic ulcer perforation: a population-based cohort study. Aliment Pharmacol Ther 2008, 28(7):895-902.

4. Thorsen K, Glomsaker TB, von Meer A, Soreide K, Soreide JA: Trends in diagnosis and surgical management of patients with perforated peptic ulcer. J Gastrointest Surg 2011, 15(8):1329-1335.

5. Bertleff MJ, Lange JF: Perforated peptic ulcer disease: a review of history and treatment. Dig Surg 2010, 27(3):161-169.

6. Lau JY, Sung J, Hill C, Henderson C, Howden CW, Metz DC: Systematic review of the epidemiology of complicated peptic ulcer disease: incidence, recurrence, risk factors and mortality. Digestion 2011, 84(2):102-113. 
7. Bae S, Shim KN, Kim N, Kang JM, Kim DS, Kim KM, Cho YK, Jung SW: Incidence and short-term mortality from perforated peptic ulcer in korea: a population-based study. J Epidemiol 2012, 22(6):508-516.

8. Moller MH, Shah K, Bendix J, Jensen AG, Zimmermann-Nielsen E, Adamsen S, Moller AM: Risk factors in patients surgically treated for peptic ulcer perforation. Scand J Gastroenterol 2009, 44(2):145-152. 142 p following 152.

9. Moller MH, Adamsen S, Thomsen RW, Moller AM: Multicentre trial of a perioperative protocol to reduce mortality in patients with peptic ulcer perforation. Br J Surg 2011, 98(6):802-810.

10. Lohsiriwat V, Prapasrivorakul S, Lohsiriwat D: Perforated peptic ulcer: clinical presentation, surgical outcomes, and the accuracy of the Boey scoring system in predicting postoperative morbidity and mortality. World J Surg 2009, 33(1):80-85.

11. Pedersen T, Eliasen K, Ravnborg M, Viby-Mogensen J, Qvist J, Johansen SH, Henriksen E: Risk factors, complications and outcome in anaesthesia. A pilot study. Eur J Anaesthesiol 1986, 3(3):225-239.

12. McCulloch P, Ward J, Tekkis PP: Mortality and morbidity in gastrooesophageal cancer surgery: initial results of ASCOT multicentre prospective cohort study. BMJ 2003, 327(7425):1192-1197.

13. Arenal JJ, Bengoechea-Beeby M: Mortality associated with emergency abdominal surgery in the elderly. Can J Surg 2003, 46(2):111-116.

14. Boey J, Choi SK, Poon A, Alagaratnam TT: Risk stratification in perforated duodenal ulcers. A prospective validation of predictive factors. Ann Surg 1987, 205(1):22-26.

15. Soreide K, Korner H, Soreide JA: Diagnostic accuracy and receiveroperating characteristics curve analysis in surgical research and decision making. Ann Surg 2011, 253(1):27-34.

16. Koc M, Yoldas O, Kilic YA, Gocmen E, Ertan T, Dizen H, Tez M: Comparison and validation of scoring systems in a cohort of patients treated for perforated peptic ulcer. Langenbecks Arch Surg 2007, 392(5):581-585.

17. Altaca G, Sayek I, Onat D, Cakmakci M, Kamiloglu S: Risk factors in perforated peptic ulcer disease: comparison of a new score system with the Mannheim Peritonitis Index. Eur J Surg 1992, 158(4):217-221.

18. Mishra A, Sharma D, Raina VK: A simplified prognostic scoring system for peptic ulcer perforation in developing countries. Indian J Gastroenterol 2003, 22(2):49-53.

19. Moller MH, Engebjerg MC, Adamsen S, Bendix J, Thomsen RW: The peptic ulcer perforation (PULP) score: a predictor of mortality following peptic ulcer perforation.A cohort study. Acta Anaesthesiol Scand 2012, 56(5):655-662

20. Saklad M: Grading of patients for surgical procedures. Anesthesiology 1941, 2:281-284.

21. Charlson ME, Pompei $P$, Ales KL, Mackenzie CR: A new method of classifying prognostic comorbidity in longitudinal studies: development and validation. J Chronic Dis 1987, 40(5):373-383.

22. Buck DL, Vester-Andersen M, Moller MH: Accuracy of clinical prediction rules in peptic ulcer perforation: an observational study. Scand J Gastroenterol 2012, 47(1):28-35.

23. Makela JT, Kiviniemi H, Ohtonen $\mathrm{P}$, Laitinen SO: Factors that predict morbidity and mortality in patients with perforated peptic ulcers. Eur J Surg 2002, 168(8-9):446-451

24. Knaus WA, Draper EA, Wagner DP, Zimmerman JE: APACHE II: a severity of disease classification system. Crit Care Med 1985, 13(10):818-829.

25. Le Gall JR, Lemeshow S, Saulnier F: A new simplified acute physiology score (SAPS II) based on a european/north american multicenter study. JAMA 1993, 270(24):2957-2963.

26. Lemeshow S, Teres D, Klar J, Avrunin JS, Gehlbach SH, Rapoport J: Mortality probability models (MPM II) based on an international cohort of intensive care unit patients. JAMA 1993, 270(20):2478-2486.

27. Egberts JH, Summa B, Schulz U, Schafmayer C, Hinz S, Tepel J: Impact of preoperative physiological risk profile on postoperative morbidity and mortality after emergency operation of complicated peptic ulcer disease. World J Surg 2007, 31(7):1449-1457.

28. Boey J, Wong J, Ong GB: A prospective study of operative risk factors in perforated duodenal ulcers. Ann Surg 1982, 195(3):265-269.

29. Wolters U, Wolf T, Stutzer H, Schroder T: ASA classification and perioperative variables as predictors of postoperative outcome. Br J Anaesth 1996, 77(2):217-222.

30. Wang CY, Lin YS, Tzao C, Lee HC, Huang MH, Hsu WH, Hsu HS: Comparison of charlson comorbidity index and kaplan-feinstein index in patients with stage I lung cancer after surgical resection. Eur J Cardiothorac Surg 2007, 32(6):877-881.
31. Ouellette JR, Small DG, Termuhlen PM: Evaluation of charlson-age comorbidity index as predictor of morbidity and mortality in patients with colorectal carcinoma. J Gastrointest Surg 2004, 8(8):1061-1067.

32. Taha AS, Angerson WJ, Prasad R, McCloskey C, Gilmour D, Morran CG: Clinical trial: the incidence and early mortality after peptic ulcer perforation, and the use of low-dose aspirin and nonsteroidal antiinflammatory drugs. Aliment Pharmacol Ther 2008, 28(7):878-885.

33. Dellinger RP, Levy MM, Carlet JM, Bion J, Parker MM, Jaeschke R, Reinhart K, Angus DC, Brun-Buisson C, Beale R, et al: Surviving sepsis campaign: international guidelines for management of severe sepsis and septic shock: 2008. Crit Care Med 2008, 36(1):296-327.

34. Schein M, Gecelter G, Freinkel Z, Gerding H: APACHE II in emergency operations for perforated ulcers. Am J Surg 1990, 159(3):309-313.

35. Dakubo JC, Naaeder SB, Clegg-Lamptey JN: Gastro-duodenal peptic ulcer perforation. East Afr Med J 2009, 86(3):100-109.

36. Arveen S, Jagdish S, Kadambari D: Perforated peptic ulcer in South India: an institutional perspective. World J Surg 2009, 33(8):1600-1604.

37. Copeland GP, Jones D, Walters M: POSSUM: a scoring system for surgical audit. Br J Surg 1991, 78(3):355-360.

38. Kumar P, Rodrigues GS: Comparison of POSSUM and P-POSSUM for riskadjusted audit of patients undergoing emergency laparotomy. Ulus Travma Acil Cerrahi Derg 2009, 15(1):19-22.

39. Mohil RS, Bhatnagar D, Bahadur L, Rajneesh, Dev DK, Magan M: POSSUM and P-POSSUM for risk-adjusted audit of patients undergoing emergency laparotomy. Br J Surg 2004, 91(4):500-503.

40. Moller MH, Adamsen S, Thomsen RW, Moller AM: Preoperative prognostic factors for mortality in peptic ulcer perforation: a systematic review. Scand J Gastroenterol 2010, 45(7-8):785-805.

41. Lee FY, Leung KL, Lai BS, Ng SS, Dexter S, Lau WY: Predicting mortality and morbidity of patients operated on for perforated peptic ulcers. Arch Surg 2001, 136(1):90-94.

42. Barut I, Tarhan OR, Cerci C, Karaguzel N, Akdeniz Y, Bulbul M: Prognostic factors of peptic ulcer perforation. Saudi Med J 2005, 26(8):1255-1259.

43. Hemmer PH, de Schipper JS, van Etten B, Pierie JP, Bonenkamp JJ, de Graaf PW, Karsten TM: Results of surgery for perforated gastroduodenal ulcers in a Dutch population. Dig Surg 2011, 28(5-6):360-366.

44. Noguiera C, Silva AS, Santos JN, Silva AG, Ferreira J, Matos E, Vilaca H: Perforated peptic ulcer: main factors of morbidity and mortality. World J Surg 2003, 27(7):782-787.

45. Larkin JO, Bourke MG, Muhammed A, Waldron R, Barry K, Eustace PW: Mortality in perforated duodenal ulcer depends upon pre-operative risk: a retrospective 10-year study. Ir J Med Sci 2010, 179(4):545-549.

46. Forsmo HM, Glomsaker T, Vandvik PO: Perforated peptic ulcer--a 12-year material. Tidsskr Nor Laegeforen 2005, 125(13):1822-1824.

47. Kocer B, Surmeli S, Solak C, Unal B, Bozkurt B, Yildirim O, Dolapci M, Cengiz $\mathrm{O}$ : Factors affecting mortality and morbidity in patients with peptic ulcer perforation. J Gastroenterol Hepatol 2007, 22(4):565-570.

48. Kujath P, Schwandner O, Bruch HP: Morbidity and mortality of perforated peptic gastroduodenal ulcer following emergency surgery. Langenbecks Arch Surg 2002, 387(7-8):298-302.

49. Kim JM, Jeong SH, Lee YJ, Park ST, Choi SK, Hong SC, Jung EJ, Ju YT, Jeong $\mathrm{CY}, \mathrm{Ha}$ WS: Analysis of risk factors for postoperative morbidity in perforated peptic ulcer. Journal of gastric cancer 2012, 12(1):26-35.

50. Arici C, Mesci A, Dincer D, Dinckan A, Colak T: Analysis of risk factors predicting (affecting) mortality and morbidity of peptic ulcer perforations. Int Surg 2007, 92(3):147-154.

51. Bas G, Eryilmaz R, Okan I, Sahin M: Risk factors of morbidity and mortality in patients with perforated peptic ulcer. Acta Chir Belg 2008, 108(4):424-427.

52. Bin-Taleb AK, Razzaq RA, Al-Kathiri ZO: Management of perforated peptic ulcer in patients at a teaching hospital. Saudi Med J 2008, 29(2):245-250.

53. Montalvo-Jave EE, Corres-Sillas O, Athie-Gutierrez C: Factors associated with postoperative complications and mortality in perforated peptic ulcer. Cir Cir 2011, 79(2):141-148.

54. Subedi SK, Afaq A, Adhikary S, Niraula SR, Agrawal CS: Factors influencing mortality in perforated duodenal ulcer following emergency surgical repair. JNMA J Nepal Med Assoc 2007, 46(165):31-35.

55. Rajesh V, Chandra SS, Smile SR: Risk factors predicting operative mortality in perforated peptic ulcer disease. Trop Gastroenterol 2003, 24(3):148-150.

56. Chalya PL, Mabula JB, Koy M, McHembe MD, Jaka HM, Kabangila R, Chandika AB, Gilyoma JM: Clinical profile and outcome of surgical 
treatment of perforated peptic ulcers in Northwestern Tanzania: A tertiary hospital experience. World J Emerg Surg 2011, 6:31.

57. Kamani F, Moghimi M, Marashi SA, Peyrovi H, Sheikhvatan M: Perforated peptic ulcer disease: mid-term outcome among Iranian population. Turk J Gastroenterol 2010, 21(2):125-128.

58. GkAKa MÜ, Ayşegül D, et al: Mortality and morbidity risk factors in the surgery of peptic ulcer perforation. Cumhuriyet Med J 2012, 34:189-193.

59. Nasio NA, Saidi H: Perforated Peptic Ulcer Disease at Kenyatta National Hospital, Nairobi. East Cent Afr J Surg 2009, 14:13-17.

60. Boey J, Wong J: Perforated duodenal ulcers. World J Surg 1987, 11(3):319-324

61. Lee FY, Leung KL, Lai PB, Lau JW: Selection of patients for laparoscopic repair of perforated peptic ulcer. Br J Surg 2001, 88(1):133-136.

62. Soreide $\mathrm{K}$ : Receiver-operating characteristic curve analysis in diagnostic, prognostic and predictive biomarker research. J Clin Pathol 2009, 62(1):1-5.

63. Owens WD, Felts JA, Spitznagel EL Jr: ASA physical status classifications: a study of consistency of ratings. Anesthesiology 1978, 49(4):239-243.

64. Grocott MP, Levett DZ, Matejowsky C, Emberton M, Mythen MG: ASA scores in the preoperative patient: feedback to clinicians can improve data quality. J Eval Clin Pract 2007, 13(2):318-319.

doi:10.1186/1757-7241-21-25

Cite this article as: Thorsen et al.: Scoring systems for outcome prediction in patients with perforated peptic ulcer. Scandinavian Journal of Trauma, Resuscitation and Emergency Medicine 2013 21:25.

\section{Submit your next manuscript to BioMed Central and take full advantage of:}

- Convenient online submission

- Thorough peer review

- No space constraints or color figure charges

- Immediate publication on acceptance

- Inclusion in PubMed, CAS, Scopus and Google Scholar

- Research which is freely available for redistribution 